\title{
Os caminhos do Caminho: O Scivias de Hildegard von Bingen e sua hermenêutica bíblica visionária
}

\author{
Martin Santos Barcala* \\ Paulo Augusto de Souza Nogueira**
}

\section{Resumo}

Este artigo examina a obra da abadessa alemã do século 12 Hildegard von Bingen. Em meio a sua prolífica e multifacetada obra se destaca Scivias (abreviatura de Scito Vias Domini, que se traduz por Conhece os Caminhos), composta de visões místicas e apocalípticas, acompanhadas de comentários exegético-teológicos e iluminuras. Discutimos as estratégias discursivas que promoviam a legitimidade de sua pregação e mensagem, em meio a um contexto institucional e teológico masculino e hierárquico. Hildegard explora o potencial de criação e atualização de mensagens dos textos bíblicos por meio de sua linguagem visionária, que é altamente conectiva e criativa. Desta forma a abadessa consegue seguir inserida no quadro institucional do catolicismo do seu tempo, de cuja hierarquia teve reconhecimento e autorização, sem abrir mão da mística visionária e de seu potencial der produção e atualização de mensagens. Analisamos mais detidamente a segunda visão do terceiro livro do Scivias, intitulada A coluna da Palavra de Deus, no texto e na iluminura, na tensão e complementariedade entre os dois, com o objetivo de explorar a relação entre os profetas bíblicos, os leitores e o Espírito, em diálogo e multiplicação de revelações.

Palavras-chave: Hildegard von Bingen, mística, visões, interpretação bíblica medieval

\section{Abstract}

This article examines the work of the German abbess of the 12th Century, Hildegard von Bingen. One of the most important among her prolific works is Scivias (shortening of Scito Vias Domini, translated as Know the Ways), composed of mystic and apocalyptic visions, followed by exegetical and theological commentaries and illuminures. We discussed the discursive strategies that legitimated her preaching and message, in a masculine and hierarchic institutional and theological context. Hildegard explores the

* Professor de Teologia da Faculdade de Teologia da Universidade Metodista de São Paulo, doutorando em Ciências da Religião na mesma universidade. martin.barcala@metodista.br

** Doutor em Teologia pela Universidade de Heidelberg, docente e pesquisador da PósGraduação em Ciências da Religião da Pontifícia Universidade Católica de Campinas. pasn777@gmail.com 


\section{Martin Santos Barcala}

Paulo Augusto de Souza Nogueira

power of creation and actualization of messages in the Biblical texts by means of her visionary language, which is highly connective and creative. In this way she could keep herself inserted in the institutional context of the Catholicism of her time, of whose hierarchy she received recognition and authorization, without giving up the mystic visionary potential for production and actualization of messages. We have closely analyzed the second vision of Scivias's third book, The Column of the Word, in its text and image, in the tension and complementarity of both, with the aim of exploring the relationship among the Biblical prophets, the readers and the Holy Spirit, in dialog and profusion of revelations.

Key-words: Hildegard von Bingen, mystic, visions, Mediavel biblical interpretatio.

\section{Los caminos del camino: Scivias de Hildegard von Bingen y su hermenéutica bíblica visionaria}

\section{Resumen}

Este artículo examina el trabajo de la abadesa alemana del siglo XII Hildegard von Bingen. En medio de su prolífica y polifacética obra, destaca Scivias (abreviatura de Scito Vias Domini, que se traduce como Conhece os Caminhos), compuesta de visiones místicas y apocalípticas, acompañadas de comentarios e iluminaciones exegéticoteológicas. Discutimos las estrategias discursivas que promovieron la legitimidad de su predicación y mensaje, en medio de un contexto institucional y teológico masculino y jerárquico. Hildegard explora el potencial para crear y actualizar mensajes de textos bíblicos a través de su lenguaje visionario, que está altamente conectado y es creativo. De esta manera la abadesa logra permanecer insertada en el marco institucional del catolicismo de su época, cuya jerarquía fue reconocida y autorizada, sin renunciar a la mística visionaria y su potencial para producir y actualizar mensajes. Analizamos más de cerca la segunda mirada del tercer libro de Scivias, titulado La columna de la Palabra de Dios, en el texto y en la iluminación, en la tensión y complementariedad entre ambos, con el objetivo de explorar la relación entre los profetas bíblicos, los lectores y el Espíritu, en diálogo y multiplicación de revelaciones.

Palabras clave: Hildegard von Bingen, mística, visiones, interpretación bíblica medieval

\section{Introdução}

O impressionante legado deixado por Hildegard von Bingen (10981179), abadessa que viveu na região do Reno e fundou seus próprios mosteiros em Rupertsberg e Eibingen, não apenas levou à sua canonização e titulação como Doutora da Igreja Católica, mas, principalmente, constituise numa fonte valiosa de pesquisa sobre diferentes aspectos da religião, espiritualidade e cultura do século 12. Hildegard figura no rol de autores e autoras cuja obra foi mais amplamente preservada dentre todos os escritores ou escritoras da Idade Média, sendo que sua composição musical é certamente a coleção mais vasta desta natureza que chegou até os dias atuais, referente ao período em que ela viveu. 
Sua obra é vastíssima e bastante diversificada, incluindo as já mencionadas composições musicais, textos litúrgicos, compêndios sobre medicina natural, escritos sobre física, narrativas hagiográficas e até mesmo um curioso glossário de Lingua Ignota, uma linguagem mística e desconhecida, que Hildegard pretendia transformar numa espécie de linguagem universal de toda humanidade para louvor a Deus, à semelhança da língua dos anjos.

Não obstante esta diversidade, existe um consenso entre estudiosos de sua obra a respeito do fato de que foram os textos originados a partir de suas visões os principais responsáveis pela fama e reconhecimento que Hildegard adquiriu em sua época e no decurso da reflexão teológica cristã posterior. Dentre eles, destacam-se Scivias, Liber vitae meritorum e Liber divinorum operum, pela ordem em que foram publicados. No período de vida da abadessa, Scivias fora sua obra mais conhecida, situação que se alterou no decorrer do tempo, haja vista a enorme repercussão posterior alcançada pelo Liber divinorum operum. No tocante ao conteúdo de suas visões, o elemento que mereceu atenção permanente e duradoura por parte de seus leitores e leitoras foram suas visões místicas, de caráter apocalíptico.

Se, à primeira vista, o conteúdo destas obras visionárias não difere muito da teologia patrística e da ortodoxia teológica e doutrinária da Igreja constituída no século 12 , bem como da tradição mística cristã vigente na Alemanha da época, a dinâmica das visões de Hildegard destoa significativamente das experiências místicas convencionais - até o limite em que seja possível agregar os adjetivos "místico" e "convencional" para designar quaisquer experiências desse tipo. A excentricidade e originalidade dos eventos narrados por Hildegard despertaram o interesse de grupos variados, constituídos tanto pelos religiosos - leigos e clérigos - de sua geração, quanto por pesquisadores de áreas bastante distintas, tais como Charles Singer - cientista e historiador que, em 1913, fez um diagnóstico retrospectivo de Hildegard como portadora de um tipo raro de enxaqueca - e Oliver Sacks, neurologista que, durante a década de 1960, corroborou as hipóteses de Singer, defendendo que as narrativas de Hildegard se enquadrariam na descrição de casos de escotoma cintilante. ${ }^{1}$

Fato é que, impressionado com as visões e narrativas de Hildegard, Bernardo de Claraval (1090-1153) recomendou a leitura de Scivias - à época

Sobre isso, veja o artigo de Katherine Foxhall (2014) que consta na bibliografia no final deste trabalho. Para os trabalhos dos próprios Singer e Sacks, veja a nota 5 da introdução de Barbara J. Newmann à edição do Scivias utilizada neste artigo. 
ainda incompleto - ao Papa Eugênio III (1088-1153), quem, por sua vez, tendo ficado bastante impactado com o conteúdo da obra, não apenas recomendou sua publicação, mas, além disso, concedeu autorização para que Hildegard expusesse suas visões e interpretações em público, algo extraordinário para mulheres naquele contexto. Porém, é por meio da correspondência da abadessa com seu então supervisor, Guibert de Gembloux, que sua própria descrição dos fenômenos vividos por ela se torna conhecida, numa passagem clássica de seu epistolário que vale a pena reproduzir:

Desde minha tenra infância, antes que meus ossos, nervos e veias estivessem plenamente fortalecidos, sempre tenho tido esta visão em minha alma, até o tempo presente, quando estou com mais de setenta anos. Nesta visão, minha alma, como se Deus a tomasse, eleva-se até a altura da abóboda celestial e do céu transitório, e se espalha entre diferentes pessoas, embora elas estejam muito distantes de mim, em terras e lugares longínquos. E porque as vejo deste modo em minha alma, eu as observo à semelhança de nuvens que passam e de outras criaturas. Eu não as escuto com meus ouvidos exteriores, nem as percebo com os pensamentos de meu coração ou por qualquer combinação de meus cinco sentidos, mas apenas em minha alma, enquanto meus olhos exteriores estão abertos. Assim, nunca fui presa do êxtase nas visões, mas eu as vejo bastante consciente, dia e noite. E sou constantemente afetada pela doença, e estou com frequência nas garras de uma dor tão intensa que ameaça me matar, mas Deus tem me sustentado até agora.

A luz que eu vejo deste modo não é espacial, mas é muito mais brilhante do que uma nuvem que carrega o sol. Não posso medir nem altura, nem comprimento, nem profundidade nela; e a chamo "o reflexo da Luz vivente". E assim como o sol, a lua e as estrelas aparecem na água, do mesmo modo escritos, sermões, virtudes e algumas ações humanas tomam forma para mim e resplandecem dentro dela.

$\mathrm{O}$ que quer que eu tenha visto ou aprendido nesta visão permanece em minha memória por um longo tempo, de modo que, quando vi ou ouvi, consigo me lembrar; e eu vejo, ouço e sei tudo de uma vez, como se num instante aprendesse o que sei. Mas aquilo que não vejo, também não sei, pois não sou educada e fui meramente ensinada a ler. E o que escrevo é aquilo que vejo e ouço na visão. Não componho qualquer palavra além daquelas que ouço, e eu as expresso num latim vulgar, assim como as escuto na visão, pois, nestas visões, não sou ensinada a escrever como os filósofos. E as palavras nesta visão não são como palavras proferidas pela boca humana, mas como uma chama flamejante, ou uma nuvem flutuando no céu limpo. Além disso, não posso mais reconhecer a forma desta luz, tanto quanto não consigo mirar diretamente a esfera solar. Algumas vezes - mas não com frequência - vejo dentro desta luz uma outra luz, que eu chamo "a Luz vivente". Não posso 
descrever quando e como a vejo, mas enquanto a vejo toda angústia e pesar me abandonam, de modo que me sinto como uma simples garota, ao invés de uma mulher idosa.

Mas, por causa da constante enfermidade que sofro, algumas vezes me canso de escrever as palavras e visões que estão lá reveladas a mim. Mesmo assim, quando minha alma as experimenta e vê, sou tão transformada que, como digo, esqueço toda dor e adversidade. E quando vejo e ouço coisas nesta visão, minha alma as bebe como se fossem de uma fonte, que, não obstante, permanece cheia e inesgotável. Em nenhum momento minha alma foi privada daquela luz que eu chamo o reflexo da Luz vivente, e eu a vejo como se estivesse contemplando um céu sem estrelas numa nuvem brilhante. Nela eu vejo as coisas que frequentemente falo, e respondo meus correspondentes a partir da radiância desta Luz vivente. ${ }^{2}$

Pelas palavras de Hildegard, é possível perceber como suas experiências transbordam os conceitos tradicionalmente aplicados para descrever fenômenos desta natureza, atravessando e reunindo características místicas, proféticas e apocalípticas. Conforme explica Caroline Walker Bynum no prefácio da edição brasileira do Scivias,

Hildegard era uma vidente profética, cujas visões tinham conteúdo político e estavam baseadas em uma experiência física de luz e de dor. [...] Uma visionária que tomou suas revelações como um texto para exegese, não uma experiência para ser revivida, Hildegard, tecnicamente falando, não era de maneira alguma uma mística. Ela não escreveu acerca de união, mas sobre doutrina, embora sua atenção aos fenômenos corporais, tais como o desejo sexual ou as cólicas menstruais, isole-a dos outros teólogos visionários do século XII (tais como Hugo ou Ricardo de São Vítor) (BYNUM, 2015, p.12). ${ }^{3}$

2 Este é um trecho clássico do epistolário de Hildegard, citado com mais ou menos detalhes em quase todos os textos dedicados à sua vida e espiritualidade. Trata-se de sua resposta - não sem muita demora, diga-se de passagem - a uma carta de Guibert de Gembloux, que a inquiria sobre a natureza de suas visões, a origem e duração dos fenômenos, o estado mental em que ela se encontrava quando as visões ocorriam e o modo pelo qual ela expressava o conteúdo das mesmas. Para este trabalho, traduzi a referida passagem a partir do texto de Barbara Newman (1985), que consta na bibliografia ao final. Uma versão um pouco abreviada está disponível em português, na introdução que Newman escreveu à edição brasileira de Scivias (2015, p.38-39).

3 Uma discussão sobre as características peculiares das experiências místicas de Hildegard, em comparação com místicos e místicas de seu tempo e posteriores, pode ser encontrada nos artigos de Karmen Mackendrick (2013) e Jeroen Deploige (1999), constantes da bibliografia ao final deste trabalho. 
A nosso ver a posição de Bynum depende demais do conceito clássico de mística como "união" com a divindade. Há outros tipos de mística. Entre eles está o modelo apocalíptico, praticado por judeus e cristãos desde a antiguidade até o Medievo, que tinha como centro a experiência de ter visões de extrema complexidade. Nesses casos raramente há qualquer experiência que possa ser chamada de "união mística'.

Esta conjunção de mística, profecia e experiência visionária apocalíptica em Hildegard é acrescida pelo reconhecimento oficial de seu ministério magistral pelo para Bento XVI, no ano de 2012, mesmo após sua canonização, que ocorrera anteriormente no mesmo ano. No documento que formaliza a concessão do título de Doutora da Igreja a Hildegard, Bento XVI enfatiza que as obras da abadessa de Rupertsberg "nascem de uma íntima experiência mística e propõem uma reflexão incisiva sobre o mistério de Deus" (BENTO XVI, 2012, \$3). O pontífice ainda destaca que "a doutrina hildegardiana é considerada eminente tanto pela profundidade e retidão das suas interpretações, como pela originalidade das suas visões" (BENTO XVI, 2012, §3).

Contudo, não obstante o inegável caráter místico e "original" das visões de Hildegard, Bento XVI não deixa margens a dúvidas sobre a ortodoxia da teologia decorrente daquelas experiências, acrescentando que "com aguda sensibilidade sapiencial e profética, Hildegard fixa o olhar no evento da revelação", mas - o que parece indispensável ressaltar - "a sua [de Hildegard] averiguação desenvolve-se a partir da página bíblica, à qual, nas fases sucessivas, permanece firmemente ancorada" (BENTO XVI, 2012, \4).

Mesmo considerando o contexto destas afirmações e tendo consciência de seu uso estratégico, haja vista que a concessão do título de Doutora da Igreja exige provas de inquestionável ortodoxia da parte outorgada, é importante notar possíveis incongruências ao se atestar, ao mesmo tempo, o caráter místico, original e ortodoxo da obra de Hildegard. Incongruências que se potencializam quando a justificativa para sua ortodoxia é exatamente a ancoragem do conteúdo de sua reflexão "nas páginas bíblicas". Se, por um lado, a temática eminentemente bíblica das visões e interpretações que Hildegard oferece é evidente, por outro, o teor, os motivos e, principalmente, os usos que ela faz das Escrituras Sagradas nas mesmas visões e interpretações são muito particulares. Haveria, dessa forma, uma incompatibilidade entre sua fidelidade à mensagem das Escrituras e a liberdade com que, por meio de visões, a interpreta?

O propósito deste trabalho é investigar o lugar que as Escrituras Sagradas ocupam na hermenêutica teológica de Hildegard, em uma de suas 
principais obras: o Scivias. Para tanto, o artigo será divido em três partes: i) apresentação da estrutura do Scivias e contextualização de sua publicação; ii) discussão sobre as principais tendências da recepção desta obra; e iii) análise da segunda visão do terceiro livro do Scivias, intitulada $A$ coluna da Palavra de Deus. Ao final, pretende-se demonstrar como os diferentes níveis de linguagem contidos em uma mesma obra teológica podem esgarçar o conceito de "ortodoxia", principalmente quando seu critério principal é a fidelidade à "página bíblica”. Entendemos que Hildegard se mostra profundamente sintonizada com o texto bíblico - com sua semântica, modelos de revelação, potencial de criação e transmissão de mensagens - nas suas formas próprias de recria-lo, de manter viva a chama profética-apocalíptica, acionando seus modos de visão, de narrar e conectar símbolos.

\section{A obra e seu mundo: a estrutura do Scivias e o contexto de sua publicação}

O termo Scivias é uma abreviação de Scito Vias Domini, que no latim significa "Conhece os caminhos do Senhor". Hildegard levou aproximadamente uma década para finalizar sua elaboração, entre 1141 e 1151, enquanto ainda era monja no mosteiro de Disibodenberg. Seu conteúdo é composto por três livros distintos, nos quais são apresentadas com detalhes as visões que a futura abadessa afirmava ter recebido de Deus. ${ }^{4}$

A estrutura tripartida da obra sugere a intenção da autora em refletir a dinâmica trinitária da teologia cristã, aplicada inclusive à história da salvação. Assim, no primeiro livro, intitulado O Criador e a Criação, Hildegard descreve seis visões que se relacionam com a criação do mundo e a revelação da Lei. O segundo livro, composto por sete visões, é dedicado ao tema da encarnação do Filho de Deus e intitulado $O$ Redentor e a Redenção. O terceiro e último livro do Scivias é bem maior que os anteriores. Sob o título de $A$ História da salvação simbolizada por um edificio, Hildegard apresenta e interpreta treze visões nas quais o drama da salvação humana é desenrolado pelo protagonismo das Virtudes - todas elas descritas por nomes e atributos femininos - e de Eclésia - a bela noiva de Cristo, que aparece já no segundo livro e ocupa o lugar de outra mulher, a Sinagoga. ${ }^{5}$

\footnotetext{
4 Todas as citações e referências ao Scivias neste trabalho são feitas a partir da versão em português publicada pela Editora Paulus, em 2015, que consta na bibliografia ao final.

5 Para uma sinopse de cada uma das visões, veja a introdução de Barbara Newmann a esta edição de Scivias, especialmente as páginas 53-80.
} 
Apesar de cada visão ser apresentada como uma unidade, é interessante observar a afirmação de Bynum no prefácio da obra, para quem "as visões de Hildegard são, na verdade, uma única visão: um manual e uma summa da doutrina cristã" (BYNUM, 2015, p.18). Barbara J. Newmann, por sua vez, sublinha o parentesco de estilo entre Hildegard e os "profetas hebraicos", que, de acordo com ela, estabeleceram "uma convenção literária [...] continuada por João de Patmos" e, "tal como eles, Hildegard estava argutamente consciente da história e de seu próprio momento histórico" (NEWMANN, 2015, p.27). Esta consciência, aliás, é o traço que aproxima as visões da abadessa mais da tradição profética do que da mística das mulheres de seu tempo. Outro indício deste parentesco estilístico pode ser encontrado nas estruturas das próprias visões, que quase unanimemente começam com a expressão "Então, vi" e terminam com a fórmula "Então, ouvi uma voz do céu...".

A este respeito, além da já referida descrição que Hildegard faz de suas próprias experiências numa carta a Guibert de Gembloux, convém atentar para a "declaração" que abre as narrativas das visões e suas subsequentes explicações alegóricas do Scivias. É nesta "declaração" que consta a informação de que no ano de 1141, quando tinha a idade de 42 anos - portanto, uma mulher já bastante madura, se comparada com a criança assustada e confusa que experimentava estes fenômenos pela primeira vez -, Hildegard teve as visões e ouviu a voz que lhe convocava a escrever e falar o que tinha recebido. No encerramento desta "declaração", a visionária inclui a fórmula mencionada por Newmann, deixando claro que "estas visões aconteceram e estas palavras foram escritas nos dias de Henrique, arcebispo de Mogúncia, e de Conrado, rei dos romanos, e de Cuno, abade de Disibodenberg, sob o Papa Eugênio" (HILDEGARD, 2015, p.98).

Evidentemente, a nomeação destas lideranças não é perfunctória, nem meramente mimética, mas já funciona como um tipo de endereçamento ideológico da própria obra. No Scivias, a intenção de Hildegard é provocar e estimular, principalmente, o clero masculino da Igreja de sua época, a quem ela acusava de viver desleixadamente, sendo negligente com a vocação de anunciar a vontade divina e cuidar do rebanho das almas e, portanto, corresponsável da proliferação da apostasia e da efervescência herética.

Dentre os desvios de conduta do clero mais atacados pela abadessa, além da timidez para proclamar a "sã doutrina", estavam o nicolaísmo - prática que relativizava a monogamia e admitia o casamento de clérigos - e a simonia - compra e venda de posições eclesiásticas. No tocante à simonia, Hildegard 
Os caminhos do Caminho: o Scivias de Hildegard 471 von Bingen e sua hermenêutica bíblica visionária

faz uma invectiva tão forte a ponto de admitir até mesmo a destituição dos líderes empossados desta maneira, algo excepcional para uma cosmovisão na qual a hierarquia social precisa ser entendida, preservada e respeitada como reflexo exterior da hierarquia celestial. Isto pode ser facilmente observado na sexta visão do terceiro livro, intitulada $O$ muro de pedra da Antiga Lei, na qual a concepção socioteológica de Hildegard é detalhada e sua defesa da obediência à ordem estabelecida é reafirmada: "Como seria legítimo que cinzas rejeitassem cinzas?", pergunta retoricamente a "Discrição", autointitulada "mãe das virtudes", que se apresenta da seguinte maneira:

Sou a mãe das virtudes, e tenho a justiça de Deus em todas as coisas. $\mathrm{Na}$ guerra espiritual e no tumulto secular, dentro de minha consciência eu sempre espero em meu Deus. Eu não condeno, não pisoteio, não repudio reis e duques, nem condes, nem os outros poderes seculares reinantes que foram ordenados pelo Soberano de todas as coisas (HILDEGARD, 2015, p.563). ${ }^{6}$

A única exceção admitida ao código de ética abraçado pela "Discrição" refere-se exatamente aos casos de simonia, quando a visionária, falando de Deus em primeira pessoa - estilo frequente em suas obras desta natureza e nem um pouco despropositado - vaticina:

E não quero que estes ministérios, que eu estabeleci, sejam tomados à força ou roubados, ou colocados à venda; quero que sejam dados por causa razoável, que aqueles que os recebem possam ser úteis a Deus e à humanidade. No entanto, há escorpiões venenosos que ignoram minha justiça, e na peçonha mortal de sua avareza e de seu orgulho, usurpam tais posições; e isso não simplesmente nos ministérios seculares, mas também nos espirituais (HILDEGARD, 2015, p.570). ${ }^{7}$

Apesar da reprovação da simonia se estender aos "ministérios seculares", ou seja, ao ordenamento político da sociedade, uma carga muito maior é lançada contra os religiosos que a praticam, pois se tratam de "pessoas espirituais dentro do status da religião e devem desprezar as coisas terrenas [tendo] obrigação muito maior de serem ardentes em imitar o sacerdócio do Filho” (HILDEGARD, 2015, p.571). Portanto,

\footnotetext{
6 Escolhi o formato padrão para referências de acordo com autor, ano de publicação e número de página, haja vista o Scivias ter apenas uma edição brasileira. Todavia, para complementar a informação, incluirei as referências conforme o modelo das obras clássicas. Assim, a passagem referida está em Scivias III, 6.7, ou seja, livro terceiro, sexta visão, sétimo item. Veja Scivias III, 6.18.
} 
se alguém desonra e usurpa uma cátedra de poder através de seu pai espiritual, o dinheiro - pois, em tal transação, o dinheiro se torna seu bispo -, ele compra a perdição para si mesmo, e tanto aquele que deu o dinheiro quanto aquele que o recebeu devem ser destituídos de suas dignidades [...] e se, mediante algum suborno secreto, ele [o ministério] for roubado e perversamente dado a um estranho, aquele que o pôs à venda e aquele que o comprou serão, ambos, justamente privados do uso dele. Com efeito, eles fizeram do templo consagrado ao meu nome um covil de ladrões (HILDEGARD, 2015, p.667). ${ }^{8}$

Mesmo consciente do poder persuasivo de suas visões, Hildegard mantém um nível relativamente elevado de pessimismo no tocante ao futuro da Igreja, especialmente pela degradação e frouxidão moral do clero. Tanto que, na famigerada visão sobre o fim dos tempos, intitulada Os últimos dias e a queda do Anticristo, a figura horripilante da besta apocalíptica é trazida à luz pela própria Eclésia, num evento catártico e polissêmico, que pode simbolizar tanto a profunda corrupção das estruturas eclesiásticas quanto a esperança de sua purificação definiSendo uma mulher e, ainda por cima, propagando críticas tão severas ao clero, não é de se surpreender que Hildegard tivesse que se defender de inúmeras acusações, além de ter que justificar de modo bastante eficiente a excepcionalidade da atuação teológica, política e pastoral para alguém de seu gênero. Durante a análise da recepção de sua obra, este cenário deve permanecer no horizonte, com vistas a evitar dois extremos: primeiro, impor sobre ela um apocalipcismo revolucionário que não condiz com seu posicionamento eclesiástico global; segundo, desconsiderar os diferentes níveis de sua linguagem teológica ou sobrestimar um destes níveis em detrimento do outro, reduzindo sua reflexão a uma espécie de compêndio ortodoxo da doutrina cristã.

No próximo tópico deste trabalho, tentar-se-á apresentar uma discussão da recepção da obra de Hildegard que leve em conta não apenas suas autodefinições, mas também algumas das principais vertentes hermenêuticas de seu legado.

\section{A santa femina indocta: estratégias discursivas e a recepção do legado teológico de Hildegard}

Além da confissão contida na carta enviada como resposta aos questionamentos de Guibert de Gembloux a respeito de seus dons e visões,

\footnotetext{
Veja Scivias III, 9.20.
} 
Os caminhos do Caminho: o Scivias de Hildegard 473 von Bingen e sua hermenêutica bíblica visionária

segundo a qual Hildegard possuía uma cultura elementar, bem menos sofisticada do que se esperaria de um exegeta, teólogo ou filósofo de seu tempo, há várias passagens no Scivias na qual a visionária recorre ao topos da ignorância e da fragilidade, sempre acompanhadas de declarações sobre dois temas: sua condição de gênero e a reafirmação de que o conteúdo das visões e suas interpretações procediam diretamente da origem divina.

Para que estas características do discurso não conduzam a uma conclusão apressada sobre a natureza ortodoxa - ou não - da obra de Hildegard, é importante atentar para o alerta feito por Newmann, de acordo com quem "para fazer jus às reivindicações excepcionais de uma mulher como Hildegard, precisamos considerar tanto a dinâmica da iluminação mística per se como sua refração através do prisma cultural e psicológico de gênero" (NEWMANN, 1985, p.175). Ou seja, não se deve desconsiderar a lateralidade de estratégias discursivas que intencionam conquistar apoio e legitimidade para o que expressa por meio das visões, superestimando apenas a dimensão mística certamente presente nas mesmas.

Esta dinâmica discursiva pode ser encontrada logo nas primeiras palavras ouvidas por Hildegard, enquanto observava sua "visão celeste", conforme sua própria descrição:

Ó frágil humano, cinza das cinzas, e imundície da imundície! Dize e escreve o que vês e ouves. Contudo, visto que és tímido no falar e simples na exposição, e iletrado no escrever, fala e escreve estas coisas não por uma boca humana e não pela compreensão da invenção humana, e não por exigências de composição humana, mas como as vês e as ouves no alto dos lugares celestes, nas maravilhas de Deus (HILDEGARD, 2015, p.95).

Se, neste parágrafo da "Declaração" que abre as visões do Scivias, a fragilidade se sobrepõe ao gênero, a voz "forte e clara" ouvida por Hildegard na primeira visão da obra já instala o problema de forma inequívoca:

Ó humano, que és frágil pó da terra e imundície da imundície! Grita e proclama a origem da pura salvação, até que aquelas pessoas sejam instruídas, aquelas que, embora vejam os mais íntimos conteúdos das Escrituras, não querem contá-los ou anunciá-los, porque elas são pusilânimes e indolentes no serviço da justiça de Deus. Descerra-lhes o confinamento dos mistérios que elas, tímidas quais são, escondem em um campo oculto e estéril. Irrompe em uma fonte de abundância e jorra conhecimento místico, até que aqueles 
que pensam que és desprezível por causa da transgressão de Eva, sejam instigados pela inundação de tua irrigação. Com efeito, recebeste tua profunda intuição não de seres humanos, mas do sublime e tremendo Juiz nas alturas... (HILDEGARD, 2015, p.104). ${ }^{9}$

Mas, nem mesmo ela consegue escapar da insegurança causada pelas possíveis reprimendas que uma mulher sofreria, caso expusesse em público o conteúdo de suas experiências visionárias. Por isso, confessa: "Eu, porém, embora visse e ouvisse estas coisas, recusei-me escrever por muito tempo, em meio à dúvida e à má opinião e à diversidade das palavras humanas" (HILDEGARD, 2015, p.97). Tal atitude, porém, seria superada corajosamente pela abadessa, não apenas pelo agravamento de seu estado de saúde que lhe deixara acamada até decidir escrever - uma inegável sugestão de que o fazia mesmo contra sua vontade -, mas, principalmente, pelo estado do clero marcado pela indolência, que a levara à conclusão de que a sua era uma "época efeminada", na qual Deus estava vocacionando mulheres para tarefa masculinas porque os homens eram tímidos.

Daí o tom autodepreciativo de suas palavras, conjugado com a reivindicação da origem divina de seu conteúdo, como se observa na décima primeira visão do terceiro livro, num tópico intitulado Por que Deus agora profere novos mistérios pela boca de uma pessoa iletrada:

Agora, no entanto, a fé católica vacila entre as nações e o Evangelho claudica entre as pessoas, e os poderosos livros em que os exímios doutores haviam condensado o conhecimento com grande cuidado, continuam sem ser lidos, devido vergonhosa apatia, e o alimento da vida, que são as divinas Escrituras, esfria à tibieza. Por essa razão, agora eu falo através de uma pessoa que não é eloquente nas Escrituras, nem ensinada por um professor terreno. Eu, que sou, falo através dela, de novos segredos e verdades místicas, ocultas até agora em livros, como alguém que mistura o barro e, em seguida, modela-o em qualquer forma que deseja (HILDEGARD, 2015, p.720). ${ }^{10}$

Porém, a despeito da fragilidade e da suposta inferioridade de gênero assumida por Hildegard, o Scivias se encerra de um modo bastante conhecido dos leitores e leitoras das Escrituras Sagradas, revelando que, provavelmente, além de legítima humildade por parte da visionária que se concebia como instrumento divino para instrução dos fiéis, outras estratégias discursivas

\footnotetext{
9 Veja Scivias I, 1.

10 Veja Scivias III, 11,18.
} 
Os caminhos do Caminho: o Scivias de Hildegard 475 von Bingen e sua hermenêutica bíblica visionária

estavam em jogo, visando o reconhecimento da autoridade dos escritos e da pregação hildegardiana. Diz a voz do céu, que conclui a obra:

E, portanto, se alguém rejeitar as palavras místicas deste livro, eu retesarei meu arco contra ele e o transfixarei pelas flechas de minha aljava; eu derrubarei a coroa de sua cabeça e farei dele como aqueles que caíram no Horeb quando murmuraram contra mim. E se alguém blasfemar contra esta profecia, que a maldição que Isaac pronunciou recaia sobre ele. Mas quem quer que a abrace e a conserve em seu coração e aplaine seus caminhos, eu o encherei com os orvalhos do céu [...] Mas quem quer que impetuosamente esconda estas palavras escritas pelo dedo de Deus, abreviando-as insanamente, ou por qualquer razão levá-las a um lugar estranho e delas zombar, que ele seja réprobo, e o dedo de Deus o esmagará (HILDEGARD, 2015, p.769). ${ }^{11}$

A alegada ignorância e rudimentariedade cultural de Hildegard é posta em cheque por Jerome Deploige (1998), num artigo no qual se propõe investigar a temática tanto numa perspectiva ideológica, ou seja, relacionando o conteúdo das visões de Hildegard com seu entorno eclesiástico imediato, para verificar em que medida as visões repercutem temas de seu cotidiano; quanto numa perspectiva cognitiva, isto é, comparando a obra de Hildegard com outros autores masculinos de sua época.

No tocante à ideologia presente nas visões e interpretações de Hildegard, Deploige afirma que "na Igreja de seu tempo, Hildegard sustentava a posição de uma reformadora de tipo conservador, alguém que queria desenvolver no interior das estruturas existentes, uma religião mais interiorizada e mais vívida" (DEPLOIGE, 1998, p.91). Acompanham-no nesta avaliação uma das principais estudiosas do legado teológico da abadessa de Rupertsberg, Barbara J. Newmann (2015), e o medievalista Constant J. Mews (2000).

Na opinião de Newmann, Hildegard fora "perversamente chamada de protoprotestante", no período das Reformas do século 16, "porque havia profetizado o confisco da riqueza eclesiástica por príncipes e a dissolução de monastérios" (NEWMANN, 2015, p.22), e também "por causa de suas profecias contra o clero negligente (NEWMANN, 2015, p.88). Para ela, é mais adequado concluir que

a obra de Hildegard presenteia-nos com uma síntese da teologia, da exegese e da espiritualidade beneditinas clássicas, tais como se encontravam em meados

$\overline{11 \quad \text { Veja Scivias III, }}$ 13,16. 
476 Martin Santos Barcala

Paulo Augusto de Souza Nogueira

do século XII, tocadas, mas ainda não profundamente permeadas pelas novas formas de piedade que já estavam mudando a face da Igreja (NEWMANN, 2015, p.84).

Assim sendo, tanto a dinâmica quanto o conteúdo das visões, como também as interpretações e declarações que Hildegard faz destas experiências, deveriam ser compreendidos como uma estratégia discursiva mais orientada para legitimar a posição de autoridade da monja dentro da estrutura eclesiástica do que provocar reformas e rupturas nesta estrutura. Nas palavras de Newmann, "suas visões são tanto um meio de inspiração divina como uma fonte de legitimação contra oponentes reais ou potenciais" (NEWMANN, 1985, p.175); e se beneficiam de três aspectos "importantes e inter-relacionados: uma experiência direta de Deus; uma fonte de verdade não-mediada; e uma forma de validação pública" (NEWMANN, 1985, p.164). Todos estes benefícios podem ser facilmente identificados na passagem que encerra o Scivias, citada acima.

Constant J. Mews, por sua vez, se debruça sobre as peculiaridades das visões apocalípticas de Hildegard, com o propósito de demonstrar que, ao invés de promulgar uma ruptura com a ordem social vigente - traço comum e distintivo da literatura deste gênero - o apocalipcismo hildegardiano apela para uma "reforma moral dentro das estruturas políticas e sociais existentes" (MEWS, 2000, p.44). De acordo com ele, "sua versão do apocalipse no Scivias não diz respeito à direção da história, mas à atuação das Virtudes na construção da cidade celestial" (MEWS, 2000, p.52). De fato, as interpretações alegóricas da visão correspondente aos últimos dias no Scivias descrevem mais a arquitetura da santidade que as Virtudes desenvolvem nas almas humanas do que os cataclismos políticos, sociais e naturais comuns nos apocalipcismos tradicionais. Portanto, Mews propõe que as visões de Hildegard no Scivias sirvam como exemplo do agenciamento do apocalipse para promover uma reforma moral, conservadora, ao invés de ser entendido inexoravelmente como uma convocação para a fuga da ordem social estabelecida.

Retornando ao artigo de Deploige, é na perspectiva cognitiva que suas hipóteses produzem achados mais interessantes. Adotando a metodologia de comparar as citações de textos bíblicos no Scivias com as obras de outros seis autores do mesmo período - Pedro Abelardo; Gautier de Saint-Victor; Pedro, o Venerável; Aelred de Rievaulx; Guibert de Gembloux; e Rupert de Deutz - Deploige conclui que a proporção das citações dos livros bíblicos 
Os caminhos do Caminho: o Scivias de Hildegard 477 von Bingen e sua hermenêutica bíblica visionária

entre eles e ela é surpreendentemente equivalente, com variações nos índices que se justificam pelo estilo e pela temática própria de cada um. ${ }^{12}$ Então, conclui Deploige,

a profunda familiaridade de Hildegard com a Bíblia não é prejudicada, em absoluto, frente a seus contemporâneos letrados. Em que se pesem a ausência de uma educação clássica nas artes liberais e sua pretendida ignorância, sua utilização da Bíblia estava em plena conformidade com as elites intelectuais de sua época (DEPLOIGE, 1999, p.98).

O quadro estatístico de Deploige instiga ainda mais a suspeita de que a alegada ignorância de Hildegard tenha uma motivação mais estratégica do que realista. Conforme ele explica:

Esta posição lhe proporcionava um argumento eficaz para distanciar-se das elites letradas e das normas canônicas. Isto fazia com que ela pudesse, como autora, trabalhar de maneira bastante criativa e, como profetisa, tomar uma posição realmente crítica frente ao clero de seu tempo. Sua ignorância lhe oferecia, em outros termos, uma independência relativamente grande para permitir-se juízos pessoais ou reprimendas. No Scivias, ela soube inclusive usar habilmente sua ignorância para estimular seus colegas masculinos em suas tarefas pastorais e assumir sua posição na História Sagrada (DEPLOIGE, 1999, p.99).

Um último aspecto da estratégia discursiva de Hildegard no Scivias investigado por Deploige merece atenção: o entrelaçamento necessário entre feminilidade e ignorância. Como bem observado por ele, "foram homens, dentre os quais seus biógrafos, que a compararam eventualmente com mulheres bíblicas como Débora ou Judite" (DEPLOIGE, 1999, p.100). De fato, nas páginas do Scivias, Hildegard não se compara com ninguém e, quando cita passagens da "página bíblica", invoca sempre patriarcas, profetas e apóstolos masculinos. Para Deploige, esta característica não é acidental, pois, nas palavras dele:

Graças à sua feminilidade, Hildegard podia utilizar sua ignorância. Esta pretendida ignorância constituía não somente um predicado funcional para justificar seu direito divino de falar e escrever de maneira teológica.

12 Sobre os dados detalhados desta comparação, veja o artigo de Jeroen Deploige incluído na bibliografia, especialmente os quadros estatísticos apresentados nas páginas 93-96. 
Com o tempo, conferiu-lhe, também, uma grande autoridade social. Como profetisa, Hildegard também necessitava de sua posição de ignorante para tomar distância; contudo, ainda podia superar sua questionada feminilidade. Ela falava e escrevia como uma médium ignorante, não como uma mulher (DEPLOIGE, 1999, p.100). ${ }^{13}$

As conclusões de Deploige já são suficientes para alertar leitores e leitoras da obra hildegardiana para esta "invisibilidade" premeditada da autora que, lançando mão de uma estratégia discursiva genial e eficiente, opera símbolos e valores de sua sociedade de modo a conquistar o interesse pela sua reflexão, bem como a autoridade necessária para expô-la ao público. Só este fato já poderia fazer emergir suspeitas quanto à "ortodoxia" de sua teologia, conduzindo a análise para lugares que transcendam seus textos e incluam, quase literalmente, as bordas de suas expressões imagético-simbólicas.

Esta é a proposta que Nathaniel M. Campbell (2013, p.19) apresenta, após ter pesquisado a participação ou interferências de Hildegard na elaboração das iluminuras que abrem as diversas visões do Scivias. Posicionando-se a favor das teses que defendem a participação ou interferência direta da abadessa neste processo, Campbell repercute as críticas de Madeleine Caviness à recepção moderna do legado hildegardiano, insistindo na tendência "logocêntrica" que prevalece nos estudos de suas obras.

Para ele, é preciso atentar para a interação entre "imagem, visão e texto" na obra de Hildegard, especialmente no Scivias (CAMPBELL, 2013, p.19-24). Isto porque, conforme explica:

Hildegard, de fato, dirigiu a iconografia e composição das imagens no manuscrito [do Scivias] na última década de sua vida, mas não meramente como uma contraparte ilustrativa do relato textual de suas experiências visionárias. Antes disso, a Doutora Visionária usava as iluminuras como um discurso teológico e visual separado, equivalente ao e interagindo com o relato textual de suas visões. As imagens não são assessórios do texto: elas estão dinamicamente integradas à obra como um todo (CAMPBELL, 2013, p.4).

A tese de Campbell é sugestiva e profícua, porque enfatiza pelo menos três níveis de linguagens distintos e autônomos na obra de Hildegard,

13. Uma análise mais rica em detalhes da estratégia detectada por Deploige pode ser encontrada num artigo de Adra Alexiu (2018), incluído na bibliografia ao final deste trabalho, e que evitei de comentar aqui por questões de restrição de espaço. 
Os caminhos do Caminho: o Scivias de Hildegard 479 von Bingen e sua hermenêutica bíblica visionária

mesmo que não necessariamente antagônicos - embora, em alguns casos, o antagonismo entre imagem, relato da visão e explicação alegórica seja evidente. Partindo deste pressuposto, Campbell desenvolverá um estudo do sentido teológico - e moral - das cores adotadas por Hildegard nas iluminuras, descortinando sentidos ausentes, inexplorados ou até contraditório, quando se consideram apenas os relatos das visões e os textos explicativos das mesmas (CAMPBELL, 2013, p.27-39). ${ }^{14}$

Diante do horizonte aberto pelos estudos de Deploige e Campbell, o terceiro e último tópico deste trabalho será dedicado à análise do lugar e da função das Escrituras Sagradas no Scivias - principalmente conforme consta da quarta visão do terceiro livro -, e orientado pela hipótese de que a estratégia discursiva adotada em toda a obra, bem como os níveis de linguagens contidos nela, torna bastante complexa e problemática a afirmação de sua ortodoxia.

\section{Um cânon sempre (re)aberto: o lugar e função das Escrituras Sagradas no Scivias}

A afirmação de que suas visões e interpretações têm um caráter revelador da vontade de Deus é recorrente na primeira obra que Hildegard tornou pública. Não é à toa que todas as seções são encerradas com um mote bastante conhecido dos leitores e leitoras do texto canônico do Apocalipse: "Mas, que aquele que vê com olhos vigilantes e ouve com ouvidos atentos acolha com um beijo minhas palavras místicas, que procedem de mim, que sou a vida". ${ }^{15}$

Deste modo, como conciliar a afirmação de Bento XVI a respeito da ancoragem da teologia de Hildegard à "página bíblica" ou a tendência ainda majoritária de alinhar o conteúdo de sua obra a uma vertente inquestionavelmente ortodoxa da teologia cristã, com as afirmações da própria abadessa sobre a natureza de sua obra? ${ }^{16}$ Como poderíamos reafirmar

14 Infelizmente, a edição brasileira da obra apresenta as iluminuras em cópias monocromáticas. Este fato, além de prejudicar o discernimento dos detalhes destas imagens, corrobora a tese de Calviness e Campbell a respeito do "logocentrismo" moderno que enviesa a recepção do legado hildegardiano.

15 Trata-se de uma fórmula de encerramento das explicações alegóricas de suas visões que Hildegard emprega, com poucas variações, em todas as seções da obra.

16 Veja, por exemplo, um dos únicos estudos disponíveis em português sobre esta obra de Hildegard, publicado por Maria Carmen Gomes Martiniano de Oliveira (2013). Logo na introdução do artigo, Oliveira (2013, p.211) vaticina: "Portanto, as ideias de Hildegard estavam em pleno acordo com a doutrina da Igreja de sua época”. Talvez, esta pressuposição, abraçada de maneira ferrenha, tenha prejudicado a exploração de uma 
Paulo Augusto de Soura Nogueira

sua "ortodoxia" - perspectiva reafirmada insistentemente por ela mesma levando em consideração seus modos de produção visionários, as inserções dos comentários e a composição das iluminuras, de forma a compor um texto emulador e - ao mesmo tempo - interpretador do texto bíblico? É o que se tentará analisar a seguir.

Já na "Declaração" que inaugura as visões do Scivias, Hildegard atesta o caráter revelatório das mesmas. Porém, naquela ocasião, as visões são apresentadas como uma espécie de exegese mística das Escrituras, conforme suas palavras: "E imediatamente eu soube o significado da explicação das Escrituras, isto é, do Saltério, do Evangelho e de outros livros católicos, tanto do Antigo quanto do Novo Testamento..." (HILDEGARD, 2015, p.96).

No decorrer da obra, diversas afirmações indicam um esquema histórico da revelação divina, na qual a Lei promulgada por Moisés - apesar de estar latente na história desde Noé - é o primeiro evento da manifestação da vontade de Deus à humanidade. A culminância deste processo é a encarnação do Filho de Deus, cujo significado teológico mais profundo, todavia, só fora alcançado e explicitado pelos pais e doutores da Igreja dos primeiros séculos da era cristã.

Na verdade, o acréscimo ao que fora ordenado pelo Filho para ser conservado pelos fiéis é visto com muito bons olhos no Scivias, postura bem diferente da ameaça feita a quem ousasse acrescentar um mínimo detalhe ao que fora revelado no texto escriturístico:

E ele deu estes escritos [Antigo e Novo Testamentos] por sua graça aos pastores da Igreja, que apascentam seu rebanho [...] Contudo, o que quer que acrescenteis, em vossa boa vontade, ao que lhes ordenei conservar, fazendo mais do que vos ordenei, eu, vosso guia e Salvador [...] recompensar-vos-ei pelo labor e pela boa vontade, com frutos adicionais [...] Quem quer que voluntariamente adicione mais do que a Lei lhe ordenou, receberá dupla recompensa; de fato, eu o considero glorioso em meu nome, visto que me amou enormemente (HILDEGARD, 2015, p.301). ${ }^{17}$

Vê-se, pois, que as Escrituras Sagradas constituem um testemunho histórico e gradativo da revelação divina na história humana, sendo invocadas inúmeras vezes pela abadessa para corroborar suas próprias interpretações

hipótese curiosa levantada por Oliveira no relato de peregrinação da alma no Scivias, a saber: a possibilidade de uma reencarnação (cf. p.228).

17 Veja Scivias II, 5,14. 
das visões. Não obstante, estas mesmas Escrituras não constituem o todo da revelação divina. Deste modo, a noção de que havia um "sentido interior" nas Escrituras Sagradas será gradativamente suplementado pela consciência de que, por meio de suas visões, Deus continuava falando "de novos segredos e de verdades místicas, ocultas até agora em livros" (HILDEGARD, 2015, p.720). Passa-se, assim, da "página bíblica" para a experiência mística e imediata das visões. Trata-se de uma hermenêutica paradoxal: parte da revelação bíblica, explora novos e inesperados elementos, que, por sua vez, trazem o leitor de volta para o centro da própria Escritura.

Na quarta visão do terceiro livro, intitulada $A$ coluna da Palavra de Deus, Hildegard descreve este esquema. É importante notar que, ao lado da coluna

Figura 1: A coluna da Palavra de Deus

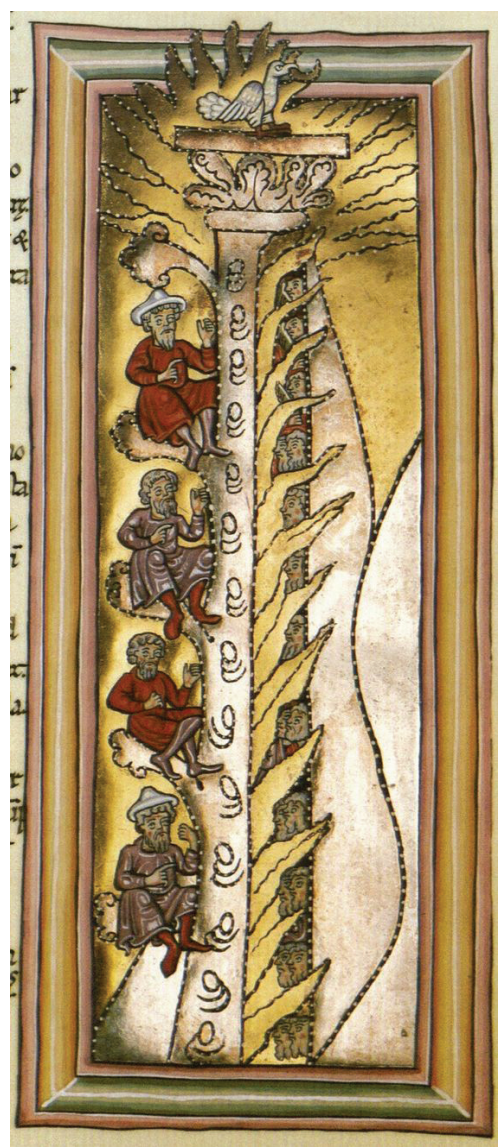
na qual figuram os patriarcas, profetas e apóstolos do Antigo e Novo Testamentos, Hildegard vê outra imagem: "A virtude do conbecimento de Deus". A composição ilustra sua compreensão da revelação divina expressada nas interpretações que se seguem. No entanto, seguindo as recomendações de Campbell, analisemos conjuntamente imagem, relato e texto, no intuito de pôr à prova o teor ortodoxo desta seção.

Uma descrição pormenorizada dos riquíssimos detalhes destas iluminuras, bem como do relato da visão a que se referem - e complementam - exigiria muito mais espaço do que dispomos aqui. Então, o foco da análise recairá ao que interessa à investigação proposta no início deste trabalho. Inicialmente, é importante que se note as cores adotadas por Hildegard para emoldurar ambas iluminuras. De acordo com Campbell (2013, p.40-46), a cor verde carrega sempre um sentido bastante positivo em Hildegard, simbolizando o verdejar (viriditas, em latim) de uma nova criação ou a renovação da criação presente: 
Paulo Augusto de Soura Nogueira

Figura 2: A virtude do Conhecimento de Deus

Inspirado na natureza, o significado fundamental do frescor e vitalidade

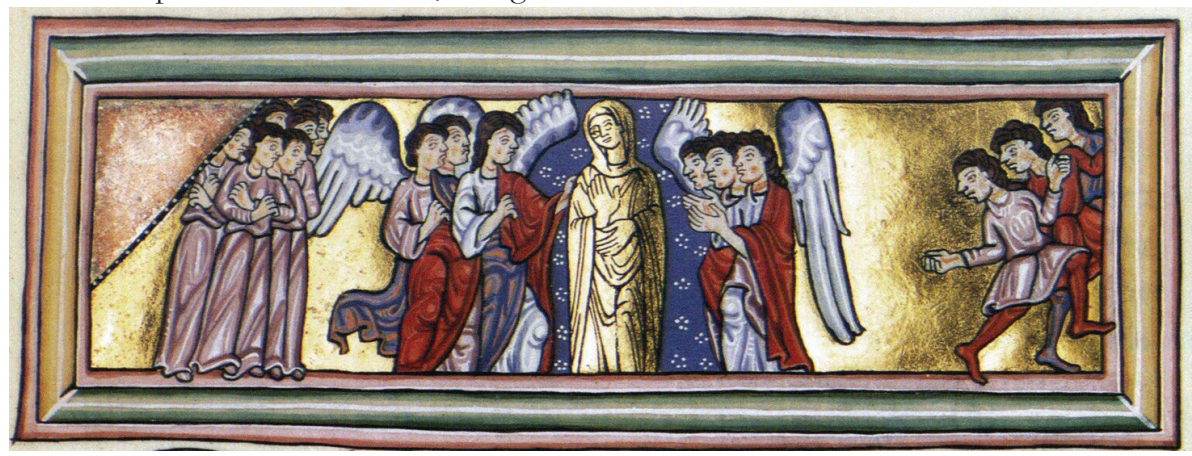

de uma folha que acabou de brotar revela muito do pensamento holístico de Hildegard. Em suas obras teológicas, o verdejar descreve a força vital essencial, tanto física quanto espiritual, que anima não apenas a humanidade, mas o mundo inteiro (CAMPBELL, 2013, p.44).

Isto está em consonância com a função das Escrituras Sagradas no Scivias, que é sempre despertar, instruir, alertar as consciências para a urgência da vontade divina em cada geração, conforme se lê num trecho da interpretação desta visão:

Efetivamente, Deus inspirou cada patriarca e profeta em seu próprio tempo a nutrir seus renovos particulares rumo à altura de seus mandamentos, e todos, em seus dias, repousaram na disposição e na ordem da justiça que lhes mostrou, fiéis e obedientes à majestade divina, conforme ela se mostrou no tempo deles (HILDEGARD, 2015, p.520).

Conforme se vê na imagem, A coluna da Palavra de Deus é dimensionada ascendentemente, tendo, no lado esquerdo, "Abraão sentado no primeiro ramo; em seguida, Moisés no segundo; depois, Josué no terceiro; e, por fim, o resto dos patriarcas e profetas, um sobre o outro, em cada ramo, sentados na ordem segundo a qual se sucederam no tempo" (HILDEGARD, 2015, p.515). As diferentes nuances de vermelho em suas vestes sugerem, sempre de acordo com Campbell, o sangue sacrificial do Filho e indicam a maior ou menor similitude entre estas personagens e o ministério de Cristo. ${ }^{18}$

Note-se, ainda, que se trata de uma coluna tripartida, sendo que na

18 A respeito deste e demais significados do vermelho nas iluminuras do Scivias, veja o artigo de Campbell (2013, p.41-46). 
"segunda quina”, da qual "saía uma radiação maravilhosamente brilhante", Hildegard situa "apóstolos, mártires, confessores e virgens, e muitos outros santos, caminhando com grande alegria” (HILDEGARD, 2015, p.515-516). Não apenas a definição destas personagens é mais difícil, como se pode observar na iluminura, por serem quantitativamente mais numerosas do que os patriarcas e profetas que ainda tateavam em suas gerações para discernir a vontade divina, haja vista terem vivido antes da encarnação do Filho, mas, o que é mais importante, estão envolvidos na radiação dourada, coloração que Campbell vincula ao significado da glória divina e à figura do Pai nas representações da Trindade (2013, p.46-48).

A terceira aresta tem o formato de um "arco retesado". Nela, não há figuras humanas e sua forma representa a dinâmica da expansão e compreensão do Evangelho que, segundo a abadessa, ainda era bastante estreita nos primeiros dias da Igreja, alcançou grande amplitude pela pregação e ensino dos doutores, e "no final dos tempos - como se fosse no cume da aresta -, os estudos de muitos se resfriarão; a sabedoria divina não lhes será atraente [...] mas eles esconderão o seu conhecimento e o guardarão para si mesmos..." (HILDEGARD, 2015, p.522-523).

No topo da coluna, vê-se uma pomba, de cujo bico procede toda radiação que perpassa as três quinas ou arestas da coluna. Trata-se da representação do Espírito Santo que, de acordo com a visionária, "fundiu o Antigo Testamento e os Evangelhos em uma única semente espiritual, da qual cresceu a justiça" (HILDEGARD, 2015, p.524). O acento pneumatológico - ao invés do tradicional fundamento cristológico - da compreensão hildegardiana da Palavra de Deus fica explícito não apenas na iluminura e no relato da visão, mas, também em sua interpretação, onde se lê que: “[...] a Palavra de Deus, conforme prefigurada no Antigo Testamento e declarada no Novo [...] mostrou no Espírito Santo três pontos de divisão. Estes eram a antiga Lei, a nova graça e a explicação dos fiéis doutores..." (HILDEGARD, 2015, p.518). Assim sendo, a circunscrição da Palavra de Deus aos textos do Antigo e Novo Testamentos, que configura postura ortodoxa, não parece ser um limite à hermenêutica de Hildegard: ela segue o cânon, mas dentro dele explora e desfruta do fluir visionário, recriando ilimitadamente o texto bíblico, guiada pelo Espírito.

Por fim, resta analisar a última parte da visão, bem como a iluminura correspondente a ela. Pela interpretação que Hildegard oferece, ficamos sabendo que a "figura de pé", vista no interior do edifício ao qual se junta 
a coluna descrita anteriormente é a "virtude do conhecimento de Deus". ${ }^{19}$ Curiosamente, no decorrer do Scivias, as "Virtudes" exercem a função de despertar a consciência, conduzir ao arrependimento, forjar a justiça e desenvolver a santidade nas almas humanas. Elas atuam diretamente na razão humana, que é uma dimensão intermediária entre a alma divina e os cinco sentidos do corpo, na concepção antropológica de Hildegard. ${ }^{20} \mathrm{Na}$ verdade, a razão se constitui na "primeira raiz fixada pela graça de Deus em cada pessoa que recebeu vida e alma” (HILDEGARD, 2015, p.555).

Destarte, na própria concepção antropológica da visionária já se evidencia a possibilidade de o ser humano conhecer a Deus naturalmente, dispensando quaisquer outras mediações históricas ou institucionais. Isto é enfatizado por Hildegard ao explicar este trecho da visão, no qual a "figura" é descrita como tendo "forma humana": "Com efeito, Deus, no poder de sua bondade, imbuiu profundamente a humanidade com a razão, e o conhecimento, e o intelecto, para que possa amá-lo encarecidamente e devotamente adorá-lo..." (HILDEGARD, 2015, p.526). Tem-se, pois, pelo relato da visão e sua interpretação, a afirmação da possibilidade de o conhecimento de Deus ser alcançado natural e universalmente, fato que, por si, relativiza consideravelmente a mediação tradicional da Escritura, permitindo cooperações e criações com ela.

Mas, apesar desta afirmação soar surpreendente aos ouvidos de quem poderia pressupor submissão inquestionável da teologia hildegardiana à letra do texto bíblico - ao menos em sua obra inaugural -, é a análise da iluminura que reserva as surpresas mais interessantes. Isto porque, conforme pode ser observado acima, a "virtude do conhecimento de Deus", descrita tanto no relato quanto na interpretação da visão em termos tão vagos quanto "figura" que tinha "forma humana", aparece na iluminura como uma mulher, vestida como uma virgem, cujas mãos estão postas num gesto de quem abençoa. As cores empregadas para pintar a mulher e o fundo sobre o qual ela aparece azul, prata e dourado - são as mesmas utilizadas para representar a Trindade. ${ }^{21}$ Uma engenhosa articulação entre imagem, relato e texto da experiência visionária que, pela sobreposição de símbolos e metáforas, permite expressar mais de um sentido para a mesma narrativa, resguardando-se de possíveis críticas opressoras que poderiam deslegitimar a obra e sua autora, ao mesmo

\footnotetext{
$19 \quad$ Veja Scivias III, 4.15

20 Para a descrição detalhada desta concepção antropológica, veja o Scivias I, 4.

21 Veja Scivias II, 2.
} 
Os caminhos do Caminho: o Scivias de Hildegard 485 von Bingen e sua hermenêutica bíblica visionária

tempo em que consolida sua mensagem e seu lugar de autoridade a despeito de seu gênero. Uma estratégia discursiva bastante eficiente para os propósitos e quem desejava ter sua mensagem ouvida.

\section{Conclusão}

A obra de Hildegard von Bingen é um continente ainda pouco explorado no Brasil. Mesmo em áreas nas quais ela é tida como principal referência para o período em que viveu, como na música e liturgia, os estudos sobre seu legado são raros. Sem dúvida, o difícil acesso às suas obras no vernáculo contribui significativamente para o seu desconhecimento no campo de quem se dedica aos estudos da religião. Todavia, aqui ainda é preciso evitar outra armadilha: o "logocentrismo". Essa fixação pelo texto escrito que despreza as sutilezas da linguagem poética, metafórica, simbólica... Como se viu no desenvolvimento deste trabalho, a obra de Hildegard comporta níveis de linguagens nem sempre unívocos e concordantes. Pode-se argumentar que a equivocidade é constitutiva da própria linguagem, quanto mais se consideramos complexa cooperação entre texto e imagem, em contexto de visões místicas e apocalípticas.

A análise do lugar e função das Escrituras Sagradas em sua reflexão teológica revela a liberdade com que ela operacionaliza os textos canônicos, rearranjando e até mesmo potencializando seus sentidos. Assim sendo, é possível concluir que sua hermenêutica teológica tem inegável inspiração bíblica, mas permanece livre e aberta para as práticas visionárias em sua hiper-conectividade, especialmente quando se leva em consideração a riqueza da junção iluminuras-texto no Scivias.

Por fim, é importante indicar o alto valor da obra de Hildegard para quem deseja trilhar os caminhos de uma teologia sensual mais do que exclusivamente moral, estética mais do que dogmática, verdadeira enquanto bela. O que não significa, obviamente, ter que fazer uma opção radical e excludente entre estes polos. Esta opção, aliás, só é exigida por quem ainda prefere dissecar exegeticamente os textos bíblicos, ao invés de se deixar embalar pelos "beijos místicos" do Sagrado. 
486 Martin Santos Barcala

Paulo Augusto de Soura Nogueira

\section{Bibliografia \\ Fonte}

HILDEGARD DE BINGEN. Scivias (Scito vias Domini): conhece os caminhos do Senhor. Tradução de Paulo Ferreira Valério. São Paulo: Paulus, 2015. 782p.

HILDEGARDIS BINGENSIS. Scivias (Corpus Christianorum). Turnholti: Brepols, 1928.

\section{Referências}

ALEXIU, Andra. Magistra magistrorum: Hildegard of Bingen as a polemicist against false teaching. In: Medieval Worlds, num. 7, 2018, p.170-189. Disponível em https://medievalworlds. net/0xc1aa5576_0x00390b0a.pdf. Acesso em 03 set 19.

BENTO XVI. Carta Apostólica: Santa Hildegarda de Bingen, Monja Professa da Ordem de São Bento, é proclamada Doutora da Igreja universal. Disponível em https://w2.vatican. va/content/benedict-xvi/pt/apost_letters/documents/hf_ben-xvi_apl_20121007_ildegardabingen.html. Acesso em 03 set 19.

BYNUM, Caroline Walker. Prefácio [à edição brasileira do Scivias. In: HILDEGARD DE BINGEN. Scivias (Scito vias Domini): conhece os caminhos do Senhor. Tradução de Paulo Ferreira Valério. São Paulo: Paulus, 2015. p.9-19.

CAMBELL, Nathaniel M. Imago expandit splendorem sum: Hildegard of Bingen's visio-theological designs in the Rupertsberg Scivias Manuscript. In: Eikón/Imago, vol. 2, n. 2, 2013, p.1-68. Disponível em http://capire.es/eikonimago/index.php/eikonimago/article/view/88/pdf. Acesso em 03 set 19.

DEPLOIGE, Jeroen. Hildegard de Bingen y su libro Scivias: ideologia y conocimientos de uma religiosa del siglo XII. In: Revista Chilena de Literatura, n.55, 1999, p.85-102. Disponível em https://revistaliteratura.uchile.cl/index.php/RCL/article/view/39218/40845. Acesso em 03 set 19 .

MACKENDRICK, Karmen. The voice of the mirror: Strange address in Hildegard of Bingen. In: Glossator: practice and theory of the commentary, vol. 7, 01 mar 2013, p. 209-226. Disponível em https://solutioperfecta.files.wordpress.com/2012/11/g7-mackendrick.pdf. Acesso em 03 set 19 .

MEWS, Constant J. From Scivias to the Liber divinorum operum: Hildegard's Apocalyptic imagination and the call to Reform. In: The Journal of Religious History, vol. 24, num. 1, fev 2000, p.44-56.

NEWMAN, Barbara J. Hildegard of Bingen: visions and validations. In: Church History, vol. 54, num. 2, jun 1985, p.163-175.

NEWMAN, Barbara J. Introdução [à edição brasileira do Scivias]. In. HILDEGARD DE BINGEN. Scivias (Scito vias Domini): conhece os caminhos do Senhor. Tradução de Paulo Ferreira Valério. São Paulo: Paulus, 2015. p.21-89.

OLIVEIRA, Maria Carmen Goes Martiniano de. A peregrinação da alma no Scivias de Hildegard de Bingen: criação, queda, redenção e salvação. In: História (São Paulo), vol. 32, num. 2, p.209-240, jul/dez 2013. Disponível em www.scielo.br/pdf/his/v32n2/a11v32n2.pdf. Acesso em 03 set 19. 
Os caminhos do Caminho: o Scivias de Hildegard 487 von Bingen e sua hermenêutica bíblica visionária

Imagens

FIGURA 1: The Pillar of the Word of God. Disponível em http://www.hildegard-society. org/2015_02_01_archive.html. Acesso em 03 set 19.

FIGURA 2: Knowledge of God. Disponível em http://nathaniel-campbell.blogspot.com/2013/12/ o-factura-dei-hildegard-of-bingen-symphonia-r-405rb.html. Acesso em 03 set 19.

Submetido em: 29-7-2020

Aceito em: 28-8-2020 